\title{
The Effect of ICT on Distance Education and Training Innovation: Perspective of Organizational Change
}

\author{
Lei Chen ${ }^{1}$ Min Wang ${ }^{1}$ \\ ${ }^{1}$ Institute of Information on Science and Technology of Agriculture, Beijing Academy of \\ Agriculture and Forestry Sciences. The Research Center of Beijing Engineering Technol- \\ ogy for Rural Remote Information Service
}

\begin{abstract}
With the development of ICT, distance education and training innovation will face more and more challenges. The authors think that it is necessary to use the theoretical framework of organizational change to research the issue of distance education and training innovation. In the authors' opinion, distance education and training innovation project includes five sections: project planning, project organization, project implementation, project control and project summary. Beijing rural modern distance education website has been selected as research case. It has shown that organization structure change and certain institutional guarantee are the premise of innovation implementation of distance education and training.
\end{abstract}

Keywords: ICT, distance education and training, organizational change, case study

\section{Introduction}

Since the reform and opening up, especially the "11th five-year plan", China's agricultural and rural information has been developed rapidly. Agricultural and rural information has become an important part of modern agriculture. With the development of ICT, An agricultural information service system what is composed of the multi-subject participations and multi-layer managements is gradually formed in rural areas. The challenges of distance education and training innovation will follow, for example to combine two-way video distance consultation, mobile information services, literature resources query and popular science cartoon spread into a unity, to develop mobile phone courses applications by means of $3 \mathrm{G}$, internet of things and mobile technology.

\section{Theory basis}

\subsection{The relationship of the two}

Distance education and training innovation put forward new requirements for website organization and management systems. In fact, distance education and training innovation is closely related to organizational change: (1)distance education and training innovation not only needs develop new training products, but also use the new marketing model;(2)organizational change need to change the current behavior and cognitive model, so overcome organizational inertia is the biggest challenge of effective implementation of organizational change; (3)both need to establish new organizational routines, such as evaluation process and performance appraisal indicators; 
(4)both need to go through a series of trial, learning and adjustment process. It follows that the implementation process of the innovation is actually a multistage process of organizational change. We can use the theoretical framework of organizational change to research the issue of distance education and training innovation.

\subsection{Distance education and training innovation of five parts}

Distance education and training innovation project includes five sections: project planning, project organization, project implementation, project control and project summary (See Fig. 1).

Project planning include: (1) develop new technical support and apply appraisal, enforce key issues research conducive to ICT technology; (2) survey the real needs of learners. Based on above-mentioned results, project team can propose work thinking, and consider some important issues such as user experience, market potential, resources supply route, technical feasibility and cost, etc. If anything, work thinking must have been adjusted.

Project organization need to (1) decomposition work tasks of distance education and training innovation by hierarchical structure; (2)match the necessary personnel, equipment, capital and knowledge resources based task list;(3) make time schedule to ensure that team leader and members use it for schedule monitoring and timely delivery.

Project implementation will signal need to complete the main tasks. Team leader should organize and coordinate the whole team to carry out research and development, design model and solution. The development of knowledge and technology plays a decisive role in the implementation of project, such as $3 \mathrm{G}$, mobile technology and streaming media transmission technology. At the same time, social development needs and train- ing requirements also play key roles of the implementation of the projects.

In project control section, team leader can timely adjust deviation through multiple means of communication and various monitoring data, as far as possible ensure implementation coincides with schedule and design model match with the work thinking.

In project summary section, the solutions of test and application are the main content. The trainees will receive their users' guides. The sponsors will assess the effect of personalized learning for subsequent reference.

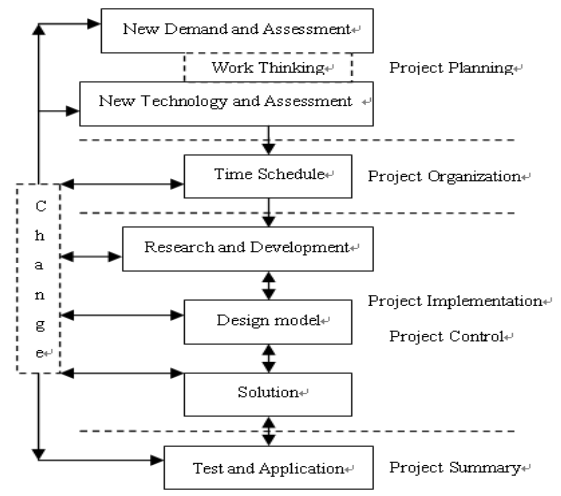

Fig.1: Distance education and training innovation process.

\section{Research design}

\subsection{Case study method and case selec- tion}

The authors choose single case study method in this paper. The reason why select case study method is that distance education and training innovation is a complex process, involving website values, norm of conduct and organizational structure, difficultly use quantitative indicators to measure. The paper's investigation aim is to uncover how to use management tools to implement distance education and training innovation. Therefore case study method is very suitable. Beijing rural modern distance 
education website has been selected as research sample. The website officially launched in 2009.At present, running platform and training team have been built up.

\subsection{Data collection and sorting out}

This study data come from three aspects: (1) the website statistics from January 2009 and December 2012, include user registration, video traffic, visits, graphic column and interactivity column traffic, etc. and (2) internal records and internal seminar that can record distance education and training innovation development and typical events, e.g. the annual department summaries, website introduction, development reports of distance education innovation team and (3)collecting and sorting the second-hand data from other website, news reports, professional magazines and periodical literatures.

In strict accordance with the theoretical framework, the data what come from various channels were divided into five parts: plan part, organization part, implementation part, control part, summary part. By longitudinal comparison, dynamic changes of website in the five management dimension reveal the relationship between organizational change and distance education and training innovation. In addition, the research effort through repeated validation and comparison between the evidences obtained as detailed information as possible to ensure the reliability and validity of data analysis. On completion, the research team asked related management practitioners to give feedback, so as to further increase the credibility of the findings.

\section{Case analysis and results}

\subsection{Project planning}

It has been found that websites open breadth and depth within a certain range will significantly improve the performance of education and training innovation. External networks knowledge sources can be used for innovation and commercialization of website technology. It is shown in three aspects: (1) design basis of training courses is to become the conjunction of user requirements and technical evaluation from only official order or the user requirements, (2) the development of training courses has begun to need the external commercial technical support, in addition to the internal support, e.g. working with external companies to develop website phase II, (3) innovative thinking of training courses pay more attention to the path and effect of external resources.

\subsection{Project organization}

Effectively distance education and training innovation requires integration of the internal organization structure. The changes include: (1) Beijing rural modern distance education website managers have formed into a specialized operation team from the initial group, (2) the evaluation of innovation project has became formative assessment form summative assessment into, (that is, becoming into the sustainable impact evaluation of agriculture, countryside and peasants), (3) performance evaluation of team members has grown into performance $(60 \%)$,development potential $(10 \%)$,team spirit $(10 \%)$, cost consciousness $(10 \%)$ and feedback $(10 \%)$ from fuzzy evaluation.

\subsection{Project implementation}

In order to guarantee the knowledge update and technology development to further promote the durability of the originality, there are three problems should be noticed: (1) education training innovation need overcome inertia, gradually set up lots of network relations with outside or- 
ganizations, such as suppliers, grass-roots management organizations, peasant households, competitors, research institutes, etc. (2) pay more attention to how to build a resource management system that can promote knowledge sharing, diffusion and transfer between internal and external websites (3) workflow is becoming more and more standardized, such as to develop a series of post responsibility and work process related to internal review, satellite receiver, broadcast monitoring, website maintenance.

\subsection{Project control}

In terms of control, (1) training innovation projects should take full account of a key property about network construction, and appropriate amend creative design based technical support , (2) a good intellectual property operation mechanism of longitudinal penetration and horizontal coordination was formed on the basis of website intellectual property management gradually regulated.

\subsection{Project summary}

The development of information technology application gradually improved training resource management system. From 2010, new development of training courses were tracked and controlled by using ICT. It was established that a relatively perfect resources support platform and database what contained basic knowledge, expert knowledge and interest knowledge. At the same time, every new development of training programs can be performed standardized assessment process such as test run, feedback and officially run.

\section{Conclusion}

Based on the organizational change theory, the paper conducted a longitudinal research to the implementation of innovation, and mainly discusses a dynamic development of innovation management. In the aspect of training innovation, rural distance education website has unique characteristics. We can further argued that: (1) organization structure change and certain institutional guarantee, such as evaluating system and resource management system, are the premise of innovation implementation of distance education and training. The formation of a specialized team marked the beginning of organizational change. The team building and resource management system are an important support innovation of distance education and training. (2) The innovation implementation process of distance education and training is often combined with pilot projects. Pilot project can further promote the construction of the external network, find and make up for a lack of internal organization management. This is single case analysis, so the conclusions still need further verification through many cases. Besides innovation management dimension, other dimensions of organization management can also be used as research angle.

\section{References}

[1] Chenjin,Wuhang and Jinjun, "How firms implement open innovation: from the perspective of organizational change," Journal of China University of Geosciences (Social Sciences Edition), pp. 74-80, Jan 2012.

[2] Ji xiaoyun, "New challenge generated by organization reform to inside control," commercial Research, pp. 98102, Jul 2012. 